Prosiding Seminar Nasional Teknologi Informasi dan Kedirgantaraan : Transformasi Teknologi untuk Mendukung Ketahanan Nasional, Yogyakarta, 13 Desember 2018

SENATIK 2018, Vol. IV, ISBN 978-602-52742-0-6

DOI: http://dx.doi.org/10.28989/senatik.v4i0.217

\title{
DESIGN OF BATIK CRAFTS INDUSTRIAL PERFORMANCE MEASUREMENT MODEL IN WUKIRSARI REGION, BANTUL Yasrin Zabidi
}

Program Studi Teknik Industri

Sekolah Tinggi Teknologi Adisutjipto

Jl. Janti Blok R Lanud Adisutjipto Yogyakarta

Email : yazma_2000@yahoo.com

\begin{abstract}
One important factor in influencing the progress and decline of an industry is the performance factor. Performance issues are not only important for middle-to-upper-level companies and large companies, but also important for small and medium industries such as the batik craft industry in the Wukirsari region, Bantul. Given the importance of performance, researchers tried to design a performance measurement model of the batik craft industry in the Wukirsari region, Bantul with the aim of identifying performance criteria, determining performance indicators, formulating performance indicators, and making performance measurement instruments. The steps in this study are divided into four phases, namely the initial research phase and problem formulation, the design phase, the analysis phase and the conclusion phase. The initial research phase and problem formulation include, the profile of the batik craft industry in the Wukirsari region, Bantul, the current performance evaluation system, problem formulation and research objectives. The design phase includes the design process of the performance measurement model with the Balanced Scorecard method which includes setting strategic objectives, establishing performance indicators (key performance indicators), determining performance indicator formulas, making performance measurement instruments. Analysis phase includes KPI analysis and strategy map analysis. Conclusion phase includes conclusions from the results of research and suggestions for the batik craft industry in Wukirsari, Bantul. From the results of the study obtained four performance perspectives based on the balanced scorecard, namely financial, customer, internal business processes, learning and growth. five, namely: increased sales growth, high customer satisfaction, improved system and better work processes, the creation of a good work climate, and increased employee productivity. There are seven performance indicators formed, namely: the rate of sales growth, the level of customer satisfaction, level of compliance with customer complaints, percentage of defective products, number of new products, level of job satisfaction, and employee productivity. The establishment of a performance measurement worksheet, so that the performance values of each performance indicator and total performance can be known in a certain period.
\end{abstract}

Keywords: Performance, Measurement, Batik

Abstrak

Salah satu faktor yang penting dalam mempengaruhi proses kemajuan dan kemunduran suatu industri adalah faktor kinerja. Masalah kinerja bukan hanya penting bagi perusahaan menengah ke atas maupun perusahaan besar, tetapi juga penting bagi industri kecil menengah seperti industri kerajinan batik di wilayah Wukirsari, Bantul. Mengingat pentingnya kinerja, peneliti mencoba untuk merancang model pengukuran kinerja industri kerajinan batik di wilayah Wukirsari, Bantul dengan tujuan mengidentifikasi kriteria-kriteria 
kinerja, menentukan indikator kinerja, membuat formula indikator kinerja, dan membuat instrumen pengukuran kinerja. Langkah-langkah dalam penelitian ini terbagi atas empat fase, yaitu fase penelitian awal dan perumusan masalah, fase perancangan, fase analisis dan fase kesimpulan. Fase penelitian awal dan perumusan masalah meliputi, profil industri kerajinan batik di wilayah Wukirsari, Bantul, sistem evaluasi kinerja saat ini, perumusan masalah dan penentuan tujuan penelitian. Fase perancangan meliputi proses perancangan model pengukuran kinerja dengan metode Balanced Scorecard yang meliputi penetapan tujuan strategik, penetapan idikator-indikator kinerja (key performance indicator, penetapan formula indikator kinerja, pembuatan instrumen pengukuran kinerja. Fase analisis meliputi analisis KPI dan analisis peta strategi. Fase kesimpulan meliputi kesimpulan dari hasil penelitian serta saran-saran bagi industri kerajinan batik di wilayah Wukirsari, Bantul. Dari hasil penelitian diperoleh empat perspektif kinerja berdasarkan balanced scorecard, yaitu finansial, pelanggan, proses bisnis internal, belajar dan tumbuh. Tujuan-tujuan strategis yang terbentuk ada lima, yaitu: pertumbuhan penjualan yang meningkat, kepuasan pelanggan yang tinggi, meningkatkan sistem dan proses kerja yang lebih baik, terciptanya iklim kerja yang baik, dan produktivitas karyawan yang meningkat. Indikator kinerja yang terbentuk ada tujuh, yaitu: tingkat pertumbuhan penjualan, tingkat kepuasan pelanggan, tingkat pemenuhan keluhan pelanggan, persentase produk cacat, jumlah produk baru, tingkat kepuasan kerja, dan tingkat produktivitas karyawan. Terbentuknya lembar kerja pengukuran kinerja, sehingga dapat diketahui nilai kinerja tiap indikator kinerja dan total kinerja dalam periode tertentu.

Kata Kunci: Kinerja, Pengukuran, Batik

\section{Pendahuluan}

Industri kerajinan batik telah banyak berkembang di wilayah Daerah Istimewa Yogyakarta, salah satunya di daerah Wukirsari, Imogiri, Kabupaten Bantul. Wukirsari merupakan salah satu sentra industri kerajinan batik yang berada di Kecamatan Imogiri, Kabupaten Bantul. Industri kerajinan batik pada dasarnya merupakan kategori industri manufaktur yang memproses input menjadi output (produk/barang).

Salah satu faktor yang penting dalam mempengaruhi proses kemajuan dan kemunduran suatu industri adalah faktor kinerja, artinya meningkatkan kinerja berarti meningkatkan kesejahteraan dan mutu perusahaan. Masalah kinerja bukan hanya penting bagi perusahaan menengah ke atas maupun perusahaan besar, tetapi juga penting bagi industri kecil menengah seperti industri kerajinan batik di wilayah Wukirsari, Imogiri Bantul. Kelancaran proses bisnis dan kemajuan usaha tidak terlepas dari peran kinerja itu sendiri. Tanpa kinerja maka matilah proses bisnis tersebut.

Industri kerajinan batik di wilayah Wukirsari merupakan salah satu bentuk kegiatan bisnis yang berada pada suatu wilayah/daerah yang memiliki peran sangat penting bagi berlangsungnya perekonomian daerah, kesejahteran masyarakat. Untuk memonitoring dan mengevaluasi kondisi industri kerajinan batik di wilayah Wukirsari, maka industri kerajinan batik tersebut perlu untuk melakukan pengukuran kinerja secara secara baik dan benar guna perbaikan berkelanjutan. Proses pengukuran kinerja yang baik dan benar didasarkan pada model pengukuran kinerja yang dibuat harus baik dan benar pula. Oleh karena itu pada penelitian ini, peneliti mencoba untuk merancang model pengukuran kinerja industri kerajinan batik di wilayah Wukirsari, Bantul.

\section{Metodologi Penelitian}

Langkah-langkah dalam penelitian ini terbagi atas empat fase, yaitu : fase penelitian awal dan perumusan masalah, fase perancangan, fase analisis dan fase kesimpulan. Fase penelitian 
awal dan perumusan masalah meliputi, profil industri kerajinan batik di wilayah Wukirsari, Bantul, sistem evaluasi kinerja saat ini, perumusan masalah dan penentuan tujuan penelitian. Fase perancangan meliputi proses perancangan model pengukuran kinerja yang meliputi penetapan tujuan strategik, penetapan idikator-indikator kinerja (key performance indicator, penetapan formula indikator kinerja, pembuatan instrumen pengukuran kinerja. Fase analisis meliputi analisis KPI dan analisis peta strategi. Fase kesimpulan meliputi kesimpulan dari hasil penelitian serta saran-saran bagi industri kerajinan batik di wilayah Wukirsari, Bantul. Adapun kerangka pemecahan penelitian ini dapat dilihat dalam gambar 1. Langkah-langkah penelitian.

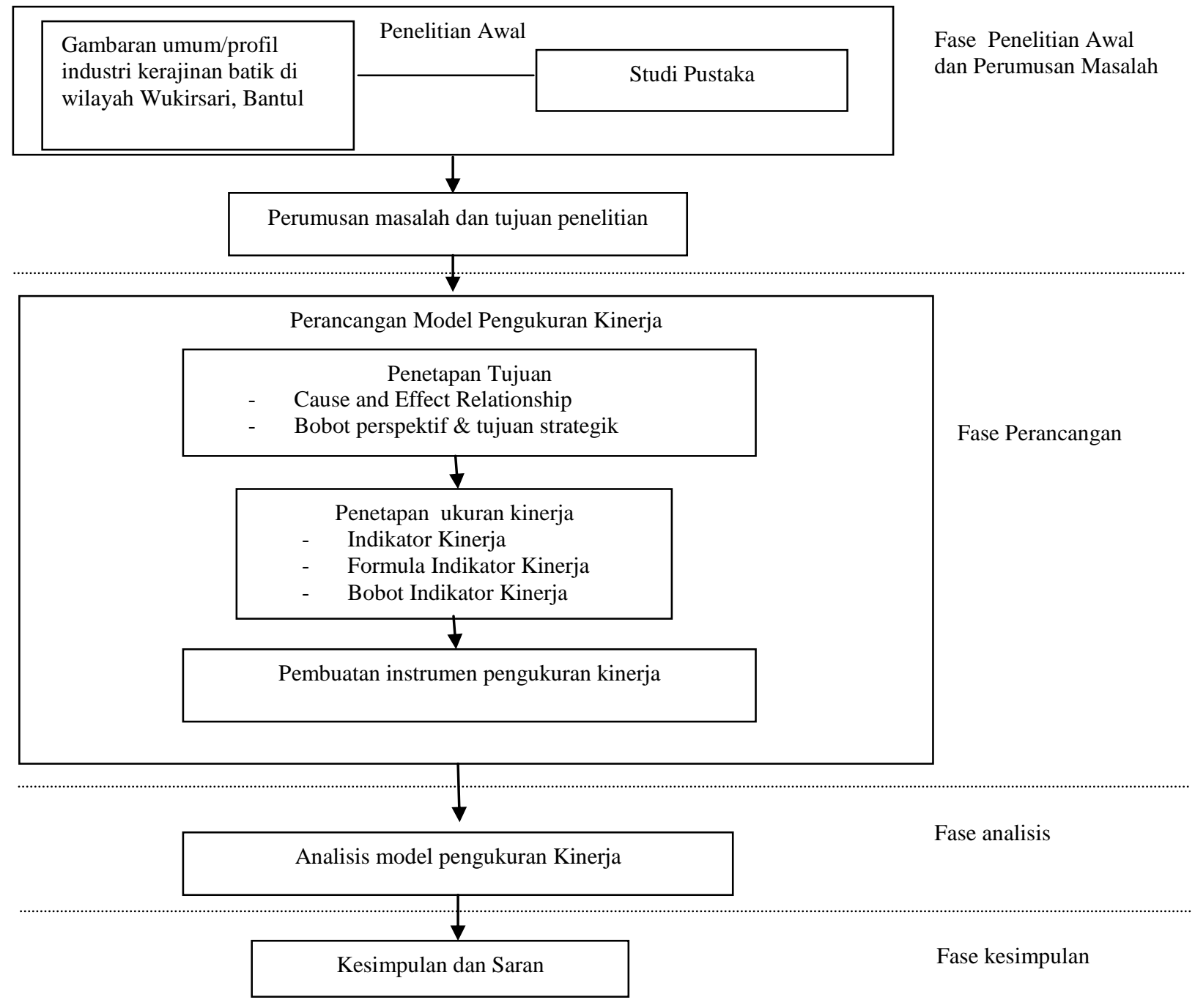

Gambar 1. Langkah-langkah Penelitian 


\section{Hasil dan Pembahasan}

\subsection{Bobot Derajat Kepentingan Perspektif}

Tabel 1. Bobot Derajat Kepentingan Perspektif

\begin{tabular}{|c|l|c|}
\hline NO & \multicolumn{1}{|c|}{ PERSPEKTIF } & BOBOT \\
\hline 1 & Perspektif Finansial & 0,40 \\
\hline 2 & Perspektif Konsumen & 0,24 \\
\hline 3 & Perspektif Proses Bisnis Internal & 0,20 \\
\hline 4 & Perspektif Belajar dan Tumbuh & 0,17 \\
\hline \multicolumn{2}{r}{ TOTAL BOBOT } & $\mathbf{1 , 0 0 0}$ \\
\hline
\end{tabular}

\subsection{Tujuan-Tujuan Strategis}

Tabel 2. Tujuan Strategis

\begin{tabular}{|l|l|l|}
\hline NO & \multicolumn{1}{|c|}{ PERSPEKTIF } & \multicolumn{1}{c|}{ TUJUAN-TUJUAN STRATEGIS } \\
\hline 1 & Finansial & 1. Pertumbuhan penjualan yang meningkat \\
\hline 2 & Pelanggan & 1. Kepuasan pelanggan yang tinggi \\
\hline 3 & $\begin{array}{l}\text { Proses Bisnis } \\
\text { Internal }\end{array}$ & $\begin{array}{l}\text { 1. } \text { Meningkatkan sistem dan proses kerja yang lebih } \\
\text { baik }\end{array}$ \\
\hline 4 & $\begin{array}{l}\text { Belajar dan } \\
\text { Pertumbuhan }\end{array}$ & $\begin{array}{l}\text { 1. } \text { Terciptanya iklim kerja yang baik } \\
\text { 2. Produktivitas karyawan yang meningkat. }\end{array}$ \\
\hline
\end{tabular}

Tujuan-tujuan strategis yang terbentuk memiliki hubungan keterkaitan antar tujuan strategis satu dengan yang lainnya (cause and effect relationship).

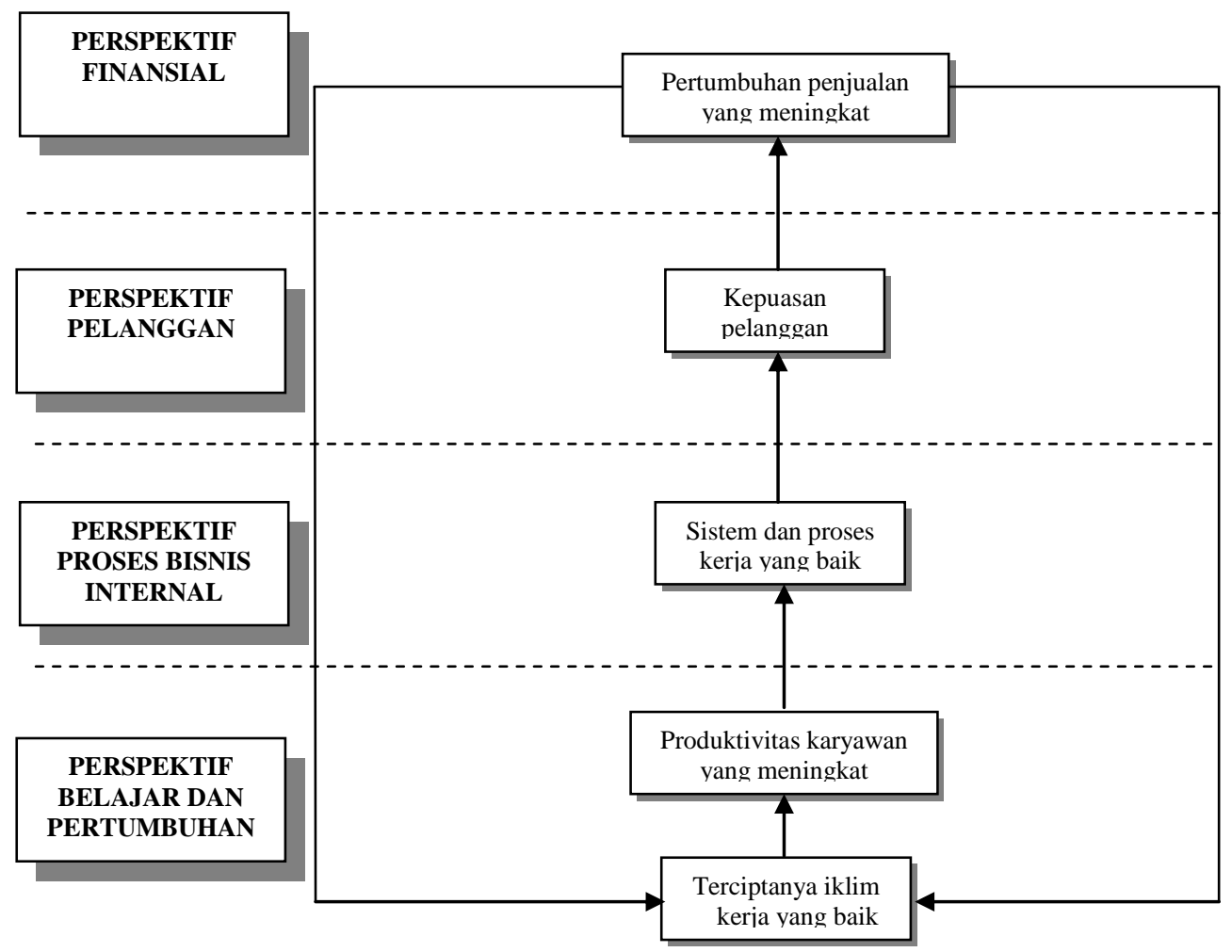

Gambar 2. Diagram Keterkaitan (cause and effect relationship) 


\subsection{Bobot Derajat Kepentingan Tujuan-Tujuan Strategis}

Tabel 3. Bobot Derajat Kepentingan Tujuan-Tujuan Strategis

\begin{tabular}{|c|l|c|}
\hline NO & \multicolumn{1}{|c|}{ TUJUAN STRATEGIS } & BOBOT \\
\hline 1 & Pertumbuhan penjualan yang mengingkat & 0,40 \\
\hline 2 & Kepuasan pelanggan yang tinggi & 0,24 \\
\hline 3 & $\begin{array}{l}\text { Meningkatkan sistem dan proses kerja } \\
\text { yang lebih baik }\end{array}$ & 0,20 \\
\hline 4 & Terciptanya iklim kerja yang baik & 0,08 \\
\hline 5 & Produktivitas karyawan yang meningkat & 0,08 \\
\hline \multicolumn{2}{|c|}{ TOTAL BOBOT } & $\mathbf{1 , 0 0}$ \\
\hline
\end{tabular}

\subsection{Penentuan Indikator Kinerja}

Penentuan KPI (Key Performance Indicators) merupakan bagian yang sangat penting dalam merancang sistem pengukuran kinerja. Oleh karena itu dalam penentuan KPI haruslah benar-benar merupakan penjabaran dari tujuan-tujuan strategis. KPI ditentukan berdasarkan tujuan-tujuan strategis yang telah dirumuskan. Adapun penjabaran tujuan-tujuan strategis kedalam KPI (Key Performance Indicators) adalah sebagai berikut:

Tabel 4. Indikator Kinerja Tiap Perspektif

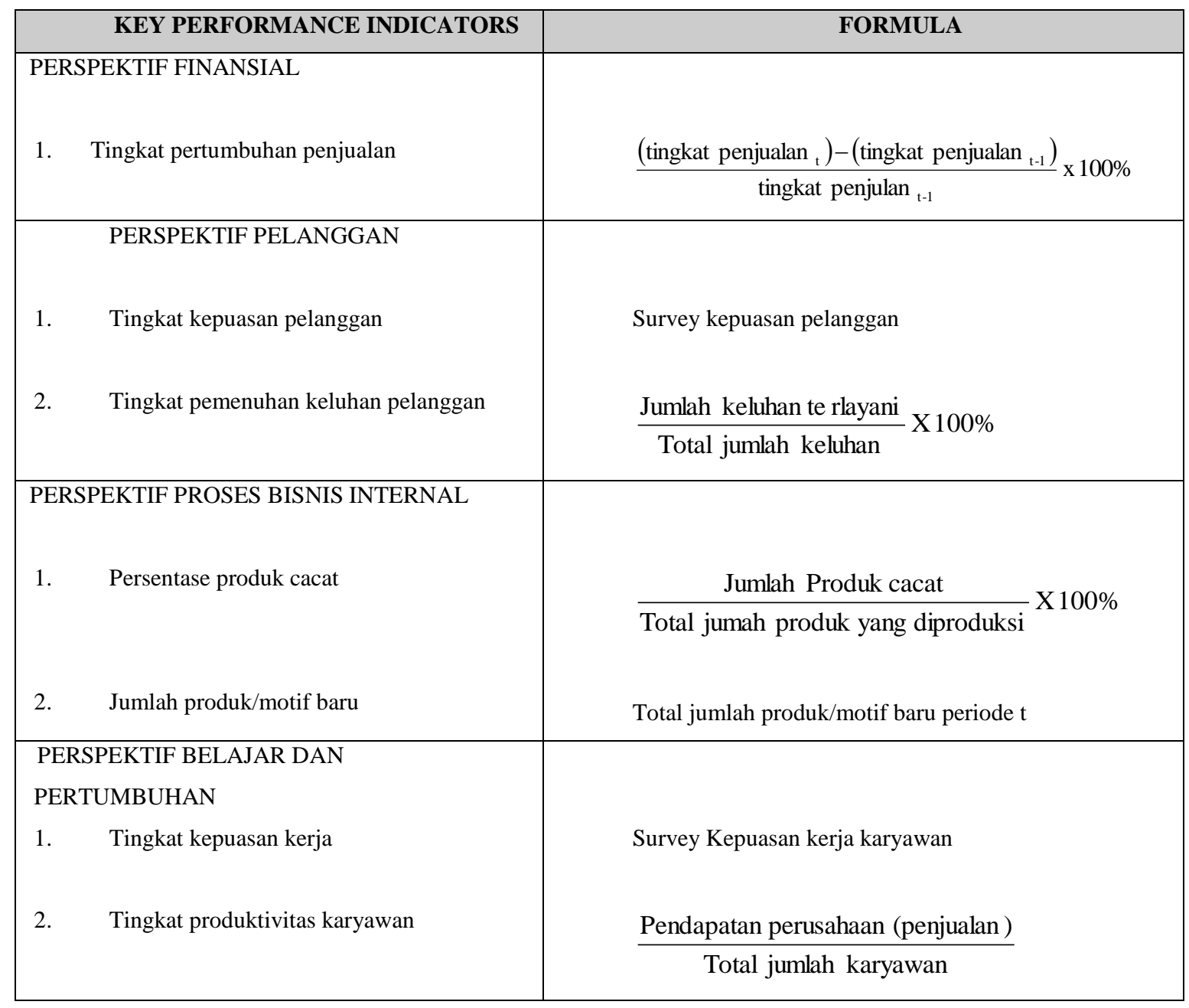




\subsection{Bobot Derajat Kepentingan Indikator Kinerja}

Tabel 5. Bobot Derajat Kepentingan Indikator Kinerja

\begin{tabular}{|c|l|c|}
\hline NO & \multicolumn{1}{|c|}{ INDIKATOR KINERJA } & BOBOT \\
\hline 1 & Tingkat pertumbuhan penjualan & 0,40 \\
\hline 2 & Tingkat kepuasan pelanggan & 0,12 \\
\hline 3 & Tingkat pemenuhan keluhan pelanggan & 0,12 \\
\hline 4 & Persentase produk cacat & 0,10 \\
\hline 5 & Jumlah produk baru & 0,10 \\
\hline 6 & Tingkat kepuasan kerja & 0,08 \\
\hline 7 & Tingkat produktivitas karyawan & 0,08 \\
\hline \multicolumn{2}{|c|}{ TOTAL BOBOT } & $\mathbf{1 , 0 0}$ \\
\hline
\end{tabular}

\subsection{Lembar Kerja Pengukuran Kinerja}

Pada bagian ini akan ditampilkan bentuk cara pengukuran kinerja berdasarkan model pengukuran kinerja yang terbentuk untuk periode pengukuran tertentu. 
Tabel 6. Bentuk Lembar Kerja Pengukuran Kinerja Tiap KPI

\begin{tabular}{|c|c|c|c|c|c|c|c|c|c|}
\hline $\begin{array}{l}\text { Indikator Kinerja } \\
\text { (KPI) }\end{array}$ & KPI 1 & KPI 2 & KPI 3 & KPI 4 & KPI 5 & KPI 6 & KPI 7 & \multirow[t]{2}{*}{ SCORE } & \multirow[t]{2}{*}{ KETERANGAN } \\
\hline Pencapaian & $11,0 \%$ & 3,0 & $92,0 \%$ & $3,2 \%$ & 4 & 3,5 & $9.000 .000,0$ & & \\
\hline Target & $15,0 \%$ & 4,0 & $100,0 \%$ & $3,0 \%$ & 5 & 4,0 & $13.000 .000,0$ & 10 & Sangat Baik \\
\hline \multirow{10}{*}{ 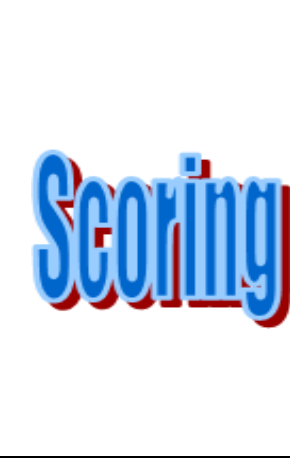 } & $14,1 \%$ & 3,9 & $98,7 \%$ & $3,1 \%$ & 5 & 3,9 & $12.142 .857,1$ & 9 & \multirow{5}{*}{ Baik } \\
\hline & $13,3 \%$ & 3,7 & $97,4 \%$ & $3,3 \%$ & 4 & 3,7 & $11.285 .714,3$ & 8 & \\
\hline & $12,4 \%$ & 3,6 & $96,1 \%$ & $3,4 \%$ & 4 & 3,6 & $10.428 .571,4$ & 7 & \\
\hline & $11,6 \%$ & 3,4 & $94,9 \%$ & $3,6 \%$ & 4 & 3,4 & $9.571 .428,6$ & 6 & \\
\hline & $10,7 \%$ & 3,3 & $93,6 \%$ & $3,7 \%$ & 4 & 3,3 & $8.714 .285,7$ & 5 & \\
\hline & $9,9 \%$ & 3,1 & $92,3 \%$ & $3,9 \%$ & 3 & 3,1 & $7.857 .142,9$ & 4 & \multirow{2}{*}{ Sedang } \\
\hline & $9,0 \%$ & 3,0 & $91,0 \%$ & $4,0 \%$ & 3 & 3,0 & $7.000 .000,0$ & 3 & \\
\hline & $8,0 \%$ & 2,8 & $89,7 \%$ & $4,7 \%$ & 3 & 2,8 & $6.333 .333,3$ & 2 & \multirow{2}{*}{ Buruk } \\
\hline & $7,0 \%$ & 2,7 & $88,3 \%$ & $5,3 \%$ & 2 & 2,7 & $5.666 .666,7$ & 1 & \\
\hline & $6,0 \%$ & 2,5 & $87,0 \%$ & $6,0 \%$ & 2 & 2,5 & $5.000 .000,0$ & 0 & Sangat Buruk \\
\hline Keterangan KPI & $\begin{array}{l}\text { Higher is } \\
\text { Better }\end{array}$ & $\begin{array}{l}\text { Higher is } \\
\text { Better }\end{array}$ & $\begin{array}{l}\text { Higher is } \\
\text { Better }\end{array}$ & $\begin{array}{l}\text { Higher is } \\
\text { Worse }\end{array}$ & $\begin{array}{l}\text { Higher is } \\
\text { Better }\end{array}$ & $\begin{array}{l}\text { Higher is } \\
\text { Better }\end{array}$ & $\begin{array}{c}\text { Higher is } \\
\text { Better }\end{array}$ & & \\
\hline Score & 5 & 3 & 4 & 9 & 6 & 6 & 5 & Total & \\
\hline Bobot & 0,40 & 0,12 & 0,12 & 0,10 & 0,10 & 0,08 & 0,08 & 1,000 & \\
\hline Nilai pencapaian & 2,00 & 0,36 & $\mathbf{0 , 4 8}$ & $\mathbf{0 , 9 0}$ & 0,60 & $\mathbf{0 , 4 8}$ & $\mathbf{0 , 4 0}$ & 5,22 & \\
\hline NilaiTarget & 4,00 & 1,20 & 1,20 & 1,00 & 1,00 & $\mathbf{0 , 8 0}$ & $\mathbf{0 , 8 0}$ & 10,00 & \\
\hline $\begin{array}{l}\text { \% Pencapaian } \\
\text { Target }\end{array}$ & $50 \%$ & $30 \%$ & $40 \%$ & $90 \%$ & $60 \%$ & $60 \%$ & $50 \%$ & & \\
\hline STATUS KINERJA & Sedang & Sedang & Sedang & Baik & Baik & Baik & Sedang & & \\
\hline
\end{tabular}


Tabel 7. Bentuk Lembar Kerja Pengukuran Total Kinerja

\begin{tabular}{|c|c|c|c|}
\hline Pencapaian & 5,22 & SCORE & KETERANGAN \\
\hline Target & 10,00 & 10 & Sangat Baik \\
\hline \multirow{10}{*}{ U. } & 9,00 & 9 & \\
\hline & 8,00 & 8 & Baik \\
\hline & 7,00 & 7 & \\
\hline & 6,00 & 6 & \\
\hline & 5,00 & 5 & \\
\hline & 4,00 & 4 & Sedang \\
\hline & 3,00 & 3 & \\
\hline & 2,00 & 2 & \\
\hline & 1,00 & 1 & Buruk \\
\hline & 0,00 & 0 & Sangat Buruk \\
\hline Keterangan KPI & Higher is Better & & \\
\hline Score & 5 & & \\
\hline Nilai Pencapaian & 5,22 & & \\
\hline NilaiTarget & $\mathbf{1 0 , 0 0}$ & & \\
\hline \% Pencapaian Target & $52 \%$ & & \\
\hline STATUS TOTAL KINERJA & Sedang & & \\
\hline
\end{tabular}


Zabidi)

\section{Kesimpulan}

1. Persepektif kriteria yang digunakan untuk pengukuran kinerja ada empat, yaitu: persepektif finansial, pelanggan, proses bisnis internal, belajar dan tumbuh.

2. Tujuan-tujuan strategis yang terbentuk ada lima, yaitu pertumbuhan penjualan yang meningkat, kepuasan pelanggan yang tinggi, meningkatkan sistem dan proses kerja yang lebih baik, terciptanya iklim kerja yang baik, dan produktivitas karyawan yang meningkat.

3. Indikator Kinerja yang terbentuk ada tujuh, yaitu tingkat pertumbuhan penjualan, tingkat kepuasan pelanggan, tingkat pemenuhan keluhan pelanggan, persentase produk cacat, jumlah produk baru, tingkat kepuasan kerja, dan tingkat produktivitas karyawan.

4. Terbentuknya lembar kerja pengukuran kinerja yang mudah digunakan, sehingga dapat diketahui nilai kinerja tiap indikator kinerja dan total kinerja dalam periode tertentu.

\section{Ucapan Terimakasih}

Peneliti mengucapkan terimakasih kepada STTA melalui P3M yang telah mendukung penelitian ini.

\section{Daftar PUSTAKA}

[1] Cullen, R. (1998). Does performance measurement improve organisational effectiveness? A post-modern analysis. In Northumbria international conference on performance measurement in libraries and information services (pp. 3-20).

[2] Kaplan, R. S., Kaplan, R. S., Norton, D. P., \& Norton, D. P. (1996). The balanced scorecard: translating strategy into action. Harvard Business Press.

[3] Mauidzoh, U., \& Zabidi, Y. (2007). Perancangan Sistem Penilaian dan Seleksi Supplier Menggunakan Multi Kriteria. Jurnal Ilmiah Teknik Industri, 5(3), 113-122.

[4] Nurdin, R., Zabidi, Y., \& Adisutjipto, S. T. T. (2005). Pengukuran dan Analisis Produktivitas Lini Produksi Pt. Xyz dengan Menggunakan Metode Objective Matrix.

[5] Parker, C. (2000). Performance measurement. Work study, 49(2), 63-66

[6] Saaty, T. L., \& Vargas, L. G. (2012). Models, methods, concepts \& applications of the analytic hierarchy process (Vol. 175). Springer Science \& Business Media

[7] Saaty, T. L. (2013). Analytic hierarchy process. In Encyclopedia of operations research and management science (pp. 52-64). Springer, Boston, MA.

[8] Simons, R., Dávila, A., \& Kaplan, R. S. (2000). Performance measurement \& control systems for implementing strategy: text \& cases. Upper Saddle River, NJ: Prentice Hall.

[9] Suwignjo, P. (2000). Sistem Pengukuran Kinerja: Sejarah Perkembangan dan Agenda Penelitian ke Depan. In Proceeding Seminar Nasional Performance Management, Bagian C, Hotel Wisata, Jakarta.

[10] Tsang, A. H., Jardine, A. K., \& Kolodny, H. (1999). Measuring maintenance performance: a holistic approach. International Journal of Operations \& Production Management, 19(7), 691-715. 
[11] Zabidi, Y. (2015). Pengukuran dan Analisis Kinerja Industri Kreatif Gerabah Kasongan Bantul Guna Meningkatkan Daya Saing dan Kekuatan Daerah. Jurnal Angkasa, 7(1).

[12] Zabidi, Y., \& Suhardiwamo, S. (2016). Perancangan Sistem Standarisasi Desa Wisata Kabupaten Bantul dengan Model Sistem Pengukuran Kinerja Balanced Scorecard Guna Penguatan Industri Pariwisata Daerah. Angkasa: Jurnal Ilmiah Bidang Teknologi, 8(2), 1-8.

[13] Zabidi, Y. (2007). Perancangan Sistem Penilaian Kinerja di STT Adisutjipto sebagai Pendukung Sistem Penjaminan Mutu. Jurnal Ilmiah Teknik Industri, 5(3), 144-152. 